\title{
Preconcentration/Separation of Palladium in Geological and Environmental Samples Based on Ionic Liquid Prior to the Determination by Flame Atomic Absorption Spectrometry
}

\author{
Chun-Gang Yuan*, Yang-Yang Zhang, and Hai-Dong Wu \\ School of Environmental Science \& Engineering, North China Electric Power University, \\ No. 619 Yonghuabei Street, Baoding 071003, Hebei Province, P. R. China
}

\section{INTRODUCTION}

Palladium (Pd) is widely used in medicine, chemical catalysts, the electrical industry, and for alloys. The main application of palladium compounds is as automotive catalyst. The high increase in palladium demand for the automotive emission control catalyst will definitely result in more palladium-containing particles released into our environment in the future. An increase in the palladium levels has been found in road dust and soil samples (1-3), which indicates that wide usage of palladium compounds may pose some environmental problems. Although palladium has not been reported as a serious environmental pollutant such as the toxic heavy metals of mercury and lead, the long-term exposure to palladium can cause adverse health effects in living beings (4). Thus, it is important to determine the trace amounts of palladium in our environment.

It is well known that palladium [Pd(II)] can be determined by various techniques including liquid chromatography and spectrophotometry (4-13). However, Pd(II) concentrations in environmental matrices are usually at trace levels, and detection is difficult because of the presence of interfering metals (14). Atomic absorption spectrometry (AAS) is regarded as the most popular and convenient instrument employed for the determination of Pd(II) despite problems caused

*Corressponding author:

E-mail: chungangyuan@botmail.com

\section{ABSTRACT}

A simple and environmentally friendly method was developed for the preconcentration, separation, and determination of palladium (Pd(II)) in geological and environmental samples. Room temperature ionic liquid (RTIL), 1-butyl-3-methylimidazolium hexafuorophosphate ([C $\left.\left.\mathrm{C}_{4} \mathrm{MIM}\right]\left[\mathrm{PF}_{6}\right]\right)$, was used for Pd(II) preconcentration and diethyldithiocarbamate (DDTC) was used as the chelating agent for extraction. The DDTC complex was extracted into the ionic liquid phase. Subsequently, Pd(II) was backextracted from the organic phase into $1 \mathrm{~mL}$ of $6 \mathrm{M}$ nitric acid solution and analyzed by flame atomic absorption spectrometry (FAAS). The parameters influencing the extraction and determination of Pd(II), such as $\mathrm{pH}$, concentration of chelating agent, extraction time and temperature, amount of ionic liquid, ionic strength, and coexisting ions were investigated and optimized.

Under the optimized experimental conditions, an enhancement factor of 29 was achieved with a $30-\mathrm{mL}$ sample. The limit of detection $(3 \sigma)$ was $2.2 \mathrm{ng} \mathrm{mL}^{-1}$, and the relative standard deviation (RSD) was 3.7\% for 7 replicates. The method was successfully validated by analyzing palladium in the certified reference material and in environmental samples with satisfactory results.

by the presence of matrix spectral interferences (5-9). However, the real concentrations of Pd(II) in most environmental samples at trace and ultratrace levels are beyond the scope of atomic absorption spectrometry (AAS). Separation and preconcentration steps are always required prior to determination by AAS in order not only to enrich the sensitivity but also to minimize the interferences caused by the matrix $(5-9,15)$. On the other hand, separation and preconcentration is also a key step in the development of techniques for the recovery of palladium from waste materials $(16,17)$.

Ionic liquids (ILs) have recently attracted special interest as environmentally friendly solvents to replace traditional toxic and volatile organic solvents (18-21). They also have negligible vapor pressure, good thermal stability, tuneable water miscibility, and are non-toxic. The application of ILs for the preconcentration and separation of analytes in analytical chemistry includes not only organic pollutants but also inorganic metals (22-28). Although ILs have in recent years been widely studied for liquid-liquid microextraction, few experiments have been carried out for palladium preconcentration (29, 30). Papaiconomou et al. (29) studied the extraction performance of several metals by hydrophobic ionic liquid without a chelating reagent. Shemirani et al. (30) extracted and determined trace levels of palladium in food additives, seawater, tea, and biological samples by using the ionic liquid 1-hexyl-3-methylimidazolium tetrafluoroborate $[\mathrm{Hmim}]\left[\mathrm{BF}_{4}\right]$ as the extractant and a UV-Vis spectrometer as the detector. These recent 
studies indicate that ionic liquids can be applied to preconcentrate and separate palladium from complex matrices effectively. However, to the best of our knowledge, there is no report about preconcentration and determination of $\mathrm{Pd}$ (II) in geological samples using ionic liquids and flame atomic absorption spectrometry (FAAS). Considering that FAAS is one of the most popular instruments for Pd(II) determination, it is very interesting and useful to establish a preconcentration method based on using ionic liquid prior to FAAS analysis.

Therefore, the aim of this study was to establish a new preconcentation and separation method based on using IL for the determination of palladium at trace levels by FAAS. Diethyldithiocarbamate (DDTC) was selected as the chelating reagent by forming the Pd-DDTC complex. The complex was extracted with the IL 1-butyl-3methylimidazolium hexafluorophosphate $\left(\left[\mathrm{C}_{4} \mathrm{MIM}\right]\left[\mathrm{PF}_{6}\right]\right)$. The extracted palladium in IL was then backextracted into a micro-volume of $6 \mathrm{M} \mathrm{HNO}_{3}$ and determined by flame atomic absorption spectrometry.

The present method was successfully applied to the determination of palladium in ore (reference material GBW 07342), fly ash, road dust, and soil samples. The advantages of this method are simplicity of operation, speed, environmental impact, and low cost with good performance.

\section{EXPERIMENTAL}

\section{Instrumentation}

An atomic absorption spectrometer (Shimadzu AA-6800, Kyoto, Japan) with a palladium hollow cathode lamp and an air-acetylene flame was used for the determination of palladium. The operating parameters were set as recommended by the manufacturer. The $\mathrm{pH}$ measurements were taken with a $\mathrm{pH}$ meter using a combined glass calomel electrode. All measurements were performed in peak height mode. A centrifuge was used to accelerate the phase separation.

\section{Reagents and Standard Solution}

All chemicals used throughout this study were at least analytical reagent grade. The standard stock solution of palladium (1000 $\left.\mathrm{mg} \mathrm{L}^{-1}\right)$ was purchased from the National Research Center for Certified Reference Materials, Beijing, P.R. China. Working solutions were prepared daily by appropriate dilution of the stock solution. Deionized water (18.2 M $\Omega$ ) was used throughout for sample preparation. The IL 1-butyl3-methylimidazolium hexafluorophosphate $\left(\left[\mathrm{C}_{4} \mathrm{MIM}\right]\left[\mathrm{PF}_{6}\right]\right)$ was purchased from Lanzhou Institute of Chemical Physics, Chinese Academy of Sciences, Lanzhou, P.R. China. The DDTC solution (1\%, w/v) was prepared by dissolving appropriate amounts of DDTC (Jinke Chemistry Reagent Company, Tianjin, P.R. China) in ethanol.

\section{Sample Collection and Preparation}

The geological standard reference material (GBW 07342, Ore) was purchased from the Institute of Geophysical and Geochemical Prospecting, Langfang, P.R. China. The road dust samples were collected from two sites with usually heavy traffic in Baoding, P.R. China. The fly ash samples were

TABLE I

FAAS Instrumental Operating Parameters

\begin{tabular}{lr}
\hline Parameters & \\
\hline Wavelength & $247.6 \mathrm{~nm}$ \\
Lamp current & $10 \mathrm{~mA}$ \\
Spectral band width & $0.5 \mathrm{~nm}$ \\
Air-acetylene flow rate & $1.8 \mathrm{~L} \mathrm{~min}^{-1}$ \\
Measurement mode & Peak area \\
Measurement time & $5 \mathrm{~s}$ \\
\hline
\end{tabular}

collected from a power plant in Baoding and the soil samples were also collected from sites near the power plant.

The ore, soil, and fly ash samples were roasted at $600^{\circ} \mathrm{C}$ for 1 hour. After cooling, they were ground, passed through an 80-mesh sieve, and then homogenized, respectively. A 2.0-g specimen of each sample was weighed into a $100-\mathrm{mL}$ beaker, A 10-mL amount of aqua regia was added to the beaker, and the mixture heated to moisten the residue. Then, another $10 \mathrm{~mL}$ of aqua regia was added to the residue and the mixture evaporated to near dryness. The insoluble part was filtered through a filter paper and washed with $1 \mathrm{M} \mathrm{HNO}_{3}$. The filtered solution was then diluted to $100 \mathrm{~mL}$ with deionized water in a marked flask.

\section{Preconcentration and Separa- tion Procedure}

The $\mathrm{pH}$ of the sample or standard solution was adjusted to the optimized value (6.5) using $1.0 \mathrm{M} \mathrm{HNO}_{3}$ or $1.0 \mathrm{M} \mathrm{NaOH}$ before extraction. A $0.5 \mathrm{~mL}$ amount of [ $\left.\mathrm{C}_{4} \mathrm{MIM}\right]\left[\mathrm{PF}_{6}\right]$ was added to a 50-mL plastic conical tube with $30 \mathrm{~mL}$ of the sample. Then, $0.5 \mathrm{~mL} \mathrm{1 \% (w/v)} \mathrm{DDTC} \mathrm{solu-}$ tion was added to the sample.

For the optimization procedures, a 30-mL amount of $1.0 \mu \mathrm{g} \mathrm{mL}^{-1}$ Pd(II) standard solution was used instead of a sample. The tube was shaken with a vortex stirrer for 10 minutes and put into a water bath at $50{ }^{\circ} \mathrm{C}$ for 5 minutes.

The Pd(II) in the sample or standard solution was complexed with the complexing reagent and extracted into the IL phase. To accelerate separation of the phases, the mixture was centrifuged at $4000 \mathrm{rpm}$ for 15 minutes after cooling. The upper aqueous phase was manually removed. The Pd(II) remained in the upper aqueous phase and was determined by FAAS for the optimization of the extraction conditions. For calibration and 
sample analysis, the Pd(II) in the IL phase was back-extracted into $1.0 \mathrm{~mL}$ of $6 \mathrm{M} \mathrm{HNO}_{3}$ solution and then determined by FAAS.

\section{RESULTS AND DISCUSSION}

\section{Effect of pH on Extraction}

One of the most important parameters influencing the efficiency of the complex formation is the $\mathrm{pH}$ of the sample. In our experiment, the influence of sample $\mathrm{pH}$ on the preconcentration of the palladium ions was investigated in the range of 2.012.0. The $\mathrm{pH}$ of the sample solution was adjusted with $1.0 \mathrm{M} \mathrm{HNO}_{3}$ and 1.0M NaOH. As can be seen in Figure 1 , the quantitative recovery of $\mathrm{Pd}(\mathrm{II})$ is achieved in the $\mathrm{pH}$ range of 5.0-8.0. The progressive decrease in extraction of palladium at a $\mathrm{pH}$ lower than 4.0 is possibly due to competition of the hydrogen ion with Pd(II) for reaction with DDTC. The decrease in extraction efficiency at a $\mathrm{pH}$ higher than 8.0 is probably due to the partial solubility of the IL phase under a high $\mathrm{pH}$. Based on the results, the $\mathrm{pH}$ of 6.5 was chosen for subsequent study, which is about the same $\mathrm{pH}$ value of deionized water.

\section{Effect of DDTC Concentration on Extraction}

In order to investigate the influence of DDTC concentration on the extraction of Pd(II), 1\% (w/v) DDTC solution was added to the sample solutions in volumes varying from 0.05 to $1.0 \mathrm{~mL}$ and the $\mathrm{pH}$ was adjusted to 6.5. After performing the extraction procedure, the extraction efficiency of Pd(II) was found to be quantitative and complete when 0.5-1.0 mL of DDTC was added (Figure 2). For subsequent experiments, the DDTC solution volume of $0.5 \mathrm{~mL}$ was used.

\section{Effect of IL Amount on Extraction}

To examine the effect of the extraction solvent volume, different volumes of IL within the 0.1-1.0 mL range were used. The results indicate that extraction can be affected by the amount of IL used (Figure 3). When $0.1 \mathrm{~mL}$ of IL was used, the extraction efficiency was low and the repetition was poor due to the difficulty of phase separation and collection of IL. Quantitative extraction can be obtained for an IL amount higher than $0.5 \mathrm{~mL}$. No obvious changes occurred on the extraction efficiency for higher amounts of IL. The extraction efficiency keeps constant when the volume of IL added was from 0.5 to $1.0 \mathrm{~mL}$. Thus, $0.5 \mathrm{~mL}$ was selected as optimum for our experiment.

\section{Effect of Ionic Strength}

Different concentrations of $\mathrm{NaNO}_{3}$ solution ranging from 0 to $1.0 \%(\mathrm{w} / \mathrm{v})$ were applied to evaluate the effects of different ionic strengths on the extraction. As can be seen in Figure 4, the extraction efficiency of Pd(II) decreases with an increase in ionic strength when the concentration of $\mathrm{NaNO}_{3}$ is higher than $0.2 \%$. The results demonstrate that the sodium ion in solution competes with the palladium ions for complexation reaction and partly increases the solubility of IL.



Influence of Temperature, Extraction Time, and Centrifuge Conditions

\section{Temperature}

Temperature can influence the transfer rate of the analyte between different phases and plays an important role in extraction. The possible influence of temperature on extraction was also investigated in the temperature range of 5 to $80{ }^{\circ} \mathrm{C}$. The sample solutions were put into a water bath for 5 minutes at different temperatures, each time after shaking. The results in Figure 5 show that an increase in temperature from 5 to $60^{\circ} \mathrm{C}$ slightly benefits the extraction process. The extraction efficiency is constant in the temperature range of 40 to $60{ }^{\circ} \mathrm{C}$. However, recovery decreases obviously when the temperature increases from $60^{\circ} \mathrm{C}$ up to $80^{\circ} \mathrm{C}$, probably owing in part to the solubility of the IL phase. Therefore, the extraction was performed at $50{ }^{\circ} \mathrm{C}$ to ensure good extraction efficiency.

\section{Extraction Time}

The study of shaking time indicate that10 minutes is enough for the extraction of Pd(II). So, a 10minute shaking time was applied for this experiment.

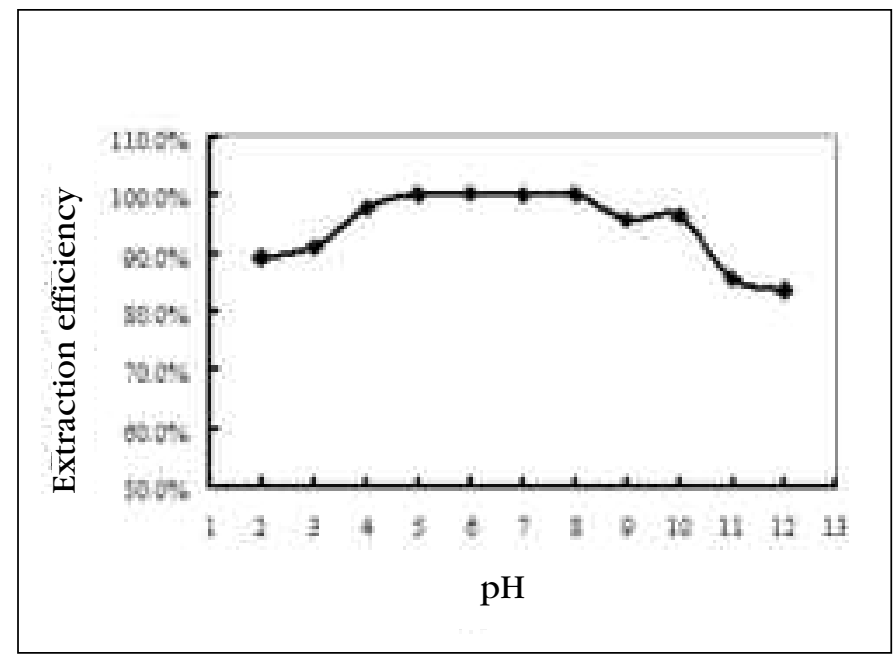

Fig. 1. Effect of $p H$ on extraction $(n=3)$.

Other conditions: $30 \mathrm{~mL}$ of $1.0 \mu g m L^{-1} d(I I)$, $0.5 \mathrm{~mL}$ of $1 \%$ $(w / v) D D T C$ $0.5 \mathrm{~mL}$ RTIL, 10 min agitation time, $50^{\circ} \mathrm{C}$ for extraction. 




Fig. 2. Effect of DDTC concentrations on extraction $(n=3)$. Other conditions: $30 \mathrm{~mL}$ of $1.0 \mathrm{\mu g} \mathrm{mL}^{-1} \mathrm{Pd}(\mathrm{II}), \mathrm{pH}=6.5$, $0.5 \mathrm{~mL}$ RTIL, $10 \mathrm{~min}$ agitation time, $50^{\circ} \mathrm{C}$ for extraction.



Fig. 4. Effect of ion strength on extraction $(n=3)$.

Other conditions: $30 \mathrm{~mL}$ of $1.0 \mathrm{\mu g} \mathrm{mL^{-1 }} \mathrm{Pd}(\mathrm{II}), 0.5 \mathrm{~mL}$ of $1 \%$ $(w / v)$ DDTC, $0.5 \mathrm{~mL}$ RTIL, $p H=6.5,10 \mathrm{~min}$ agitation time, $50{ }^{\circ} \mathrm{C}$ for extraction.

\section{Centrifugation Rate and Time}

The effect of centrifugation rate on the recovery was studied from $1000-5000 \mathrm{rpm}$. It was found that over the rate of $4000 \mathrm{rpm}$, the phases can be separated completely. The results of recovery indicate that a 15 minute centrifugation rate was enough to achieve complete transfer of the room temperature ionic liquid (RTIL) phase to the bot-

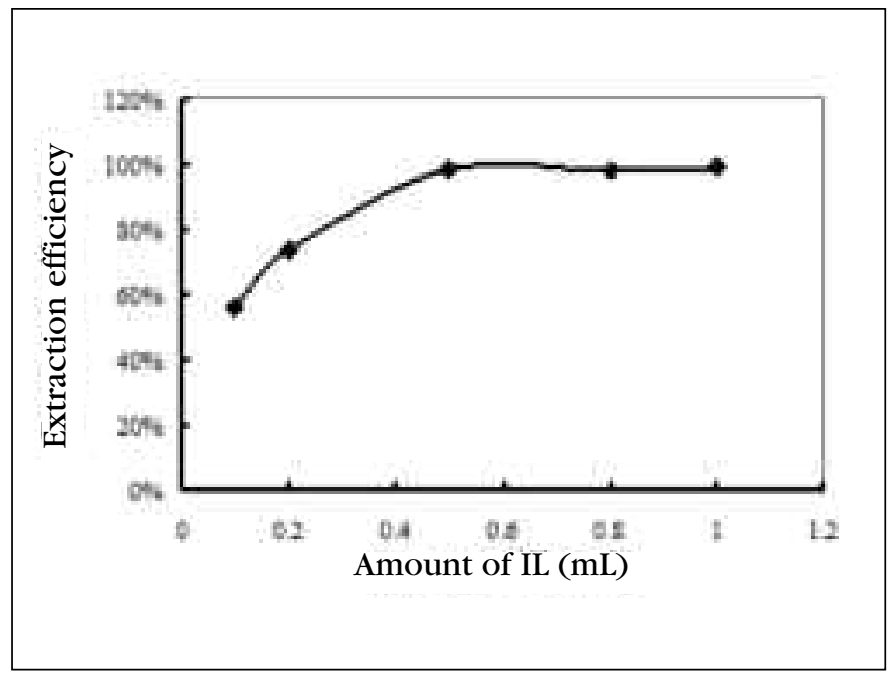

Fig. 3. Effect of amounts of IL on extraction ( $n=3)$.

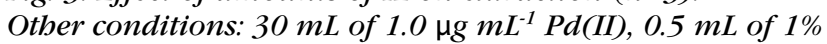
$(w / v)$ DDTC, $p H=6.5,10$ min agitation time, $50{ }^{\circ} \mathrm{C}$ for extraction.

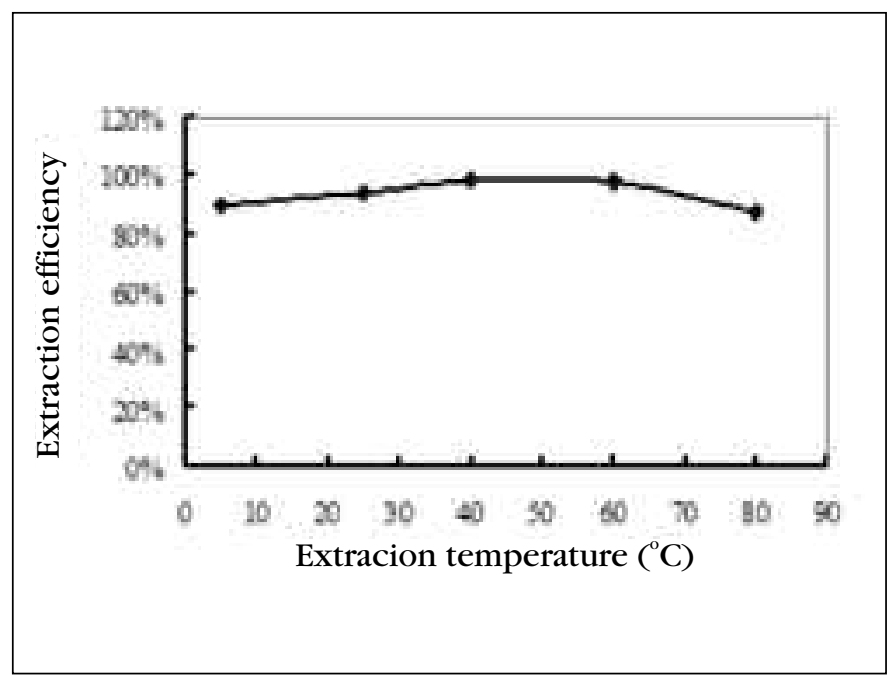

Fig. 5. Effect of temperature on extraction $(n=3)$.

Other conditions: $30 \mathrm{~mL}$ of $1.0 \mu \mathrm{g} \mathrm{mL} \mathrm{L}^{-1} \mathrm{Pd}(\mathrm{II}), \mathrm{pH}=6.5,0.5 \mathrm{~mL}$ of $1 \%(w / v)$ DDTC, $0.5 \mathrm{~mL}$ RTIL, 10 min agitation time. tom of the centrifuge tube. For this experiment, $4000 \mathrm{rpm}$ and $15 \mathrm{~min}$ utes were chosen for subsequent experiments.

\section{Optimization of Back-Extraction}

To apply this preconcentration and separation method to the determination of Pd(II) in samples by FAAS analysis, different back-extraction processes were evaluated. Due to the high viscosity of IL, it is not possible to directly inject the IL phase into the FAAS for analysis. Therefore, one approach to backextraction of Pd(II) from the IL phase to the aqueous phase has to be used. Decreasing the $\mathrm{pH}$ of the media can lead to dissociation of the Pd-DDTC complex and further release palladium ions from the IL phase into the aqueous phase. Dif- 
ferent mineral acids and other solutions at different levels were tested for Pd(II) back-extraction. The recoveries of back-extraction were achieved by using different solutions which are listed in Table II. Our study shows that $6 \mathrm{M} \mathrm{HNO}_{3}$ can quantitatively extract $\mathrm{Pd}(\mathrm{II})$ from the IL phase. Therefore, $1.0 \mathrm{~mL}$ of $6 \mathrm{M} \mathrm{HNO}_{3}$ was selected as the best choice.

In addition, the effects of temperature on back-extraction were investigated. Before shaking the solutions, the samples were kept in water baths at various temperatures for 5 minutes. The results show that the recovery increases as temperature increases from 5 to $60{ }^{\circ} \mathrm{C}$. Thus, $60{ }^{\circ} \mathrm{C}$ was selected for backextraction.

Agitation time can also affect quantitative back-extraction of Pd(II) from the IL phase into the aqueous phase. The effect of agitation time on back-extraction was studied by varying the time from 0.5 to 10 minutes. It was found that the analyte in IL can be recovered completely in 3 minutes. To minimize the deviation of extraction efficiency between different batches, 5 minutes was chosen as the optimum agitation time.

TABLE II

Evaluation of Different Back-Extraction Processes for Releasing Pd(II) From the IL Phase

\begin{tabular}{ll}
\hline $\begin{array}{l}\text { Back-Extraction } \\
\text { Process }^{\mathrm{a}}\end{array}$ & Recovery (\%) \\
\hline $0.1 \mathrm{M} \mathrm{Na}_{2} \mathrm{~S}_{2} \mathrm{O}_{3}$ & $26 \pm 5$ \\
$0.2 \mathrm{M} \mathrm{Na}_{2} \mathrm{~S}_{2} \mathrm{O}_{3}$ & $39 \pm 4$ \\
$0.5 \mathrm{M} \mathrm{Na}_{2} \mathrm{~S}_{2} \mathrm{O}_{3}$ & $57 \pm 5$ \\
$1 \mathrm{M} \mathrm{Na}_{2} \mathrm{~S}_{2} \mathrm{O}_{3}$ & $61 \pm 6$ \\
$1 \% \mathrm{Thiourea}$ & $65 \pm 4$ \\
$3 \% \mathrm{Thiourea}$ solution (w/v) & $69 \pm 8$ \\
$2 \mathrm{M} \mathrm{HCl}$ & $21 \pm 5$ \\
$6 \mathrm{M} \mathrm{HCl}$ & $47 \pm 7$ \\
$2 \mathrm{M} \mathrm{HNO}$ & $63 \pm 3$ \\
$6 \mathrm{M} \mathrm{HNO}_{3}$ & $97 \pm 4$ \\
\hline
\end{tabular}

\footnotetext{
a The volume of the back-extraction solvent is $1.0 \mathrm{~mL}$.
}

\section{Interferences Study}

The effect of coexisting ions on the extraction of Pd(II) was investigated by keeping the concentration of $\mathrm{Pd}(\mathrm{II})$ at $1.0 \mu \mathrm{g} \mathrm{mL}^{-1}$. The concentrations of commonly coexisting ions were in the $500 \mathrm{ng} \mathrm{mL}^{-1}$ to $2000 \mu \mathrm{g} \mathrm{mL}^{-1}$ range. Preconcentration was carried out according to the recommended procedure. The tolerance limit of coexisting ions is defined as the largest amount causing variations of less than 5\% in the recovery of the analyte (26). The results are given in Table III. It can be concluded that all anions and cations tested did not result in significant interferences. The results also indicate that $\mathrm{Pd}$ (II) can be effectively separated from these ions by the recommended separation and preconcentration procedure. The tolerance of coexisting ions enabled us to apply the method to real sample analysis.

\section{Analytical Performances}

A calibration graph was constructed under the optimum extraction conditions. A $0.5-\mathrm{mL}$ amount of IL and $30 \mathrm{~mL}$ of standard solutions at different concentrations were used. The extracted Pd(II) in the IL phase was back-extracted into $1.0 \mathrm{~mL}$ of $6 \mathrm{M} \mathrm{HNO}_{3}$. Then, $\mathrm{Pd}(\mathrm{II})$ in the back-extraction solution was determined by FAAS.

Table IV summarizes the analytical characteristics of the preconcentation method. The linear concentration ranged from 10.0 to $500 \mathrm{ng} \mathrm{mL}^{-1}$. The calibration function was $\mathrm{Y}=0.0005 \mathrm{C}+0.0003$, where $\mathrm{Y}$ was the peak height of the FAAS signal and $\mathrm{C}$ was the concentration of palladium in $\mathrm{ng} \mathrm{mL}^{-1}$. A satisfactory correlation coefficient $\left(r^{2}=0.9923\right)$ and deviations ( $\mathrm{RSD}=3.7 \%$ ) were obtained with a limit of detection $(3 \sigma)$ of $2.2 \mathrm{ng} \mathrm{mL}^{-1}$. The enhancement factor, which was calculated

TABLE III

Tolerance of Concentration of Coexisting Ions in the Extraction of Pd(II) ${ }^{\mathbf{a}}$

\begin{tabular}{cc}
\hline Coexisting Ion & Concentration $\left(\mathrm{ng} \mathrm{mL}^{-1}\right)$ \\
\hline $\mathrm{NO}_{3}{ }^{-}$ & $2000^{*}$ \\
$\mathrm{Cl}^{-}$ & $100^{*}$ \\
$\mathrm{CO}_{3}{ }^{2-}$ & $10^{*}$ \\
$\mathrm{SO}_{4}{ }^{2-}$ & $10^{*}$ \\
$\mathrm{Mg}^{2+}$ & 1000 \\
$\mathrm{Mn}^{2+}$ & 1000 \\
$\mathrm{Fe}^{3+}$ & 1000 \\
$\mathrm{Fe}^{2+}$ & 1000 \\
$\mathrm{Cu}^{2+}$ & 1000 \\
$\mathrm{Zn}^{2+}$ & 1000 \\
$\mathrm{Al}^{3+}$ & 1000 \\
$\mathrm{Cd}^{2+}$ & 500 \\
$\mathrm{Co}^{2+}$ & 500 \\
$\mathrm{Ni}^{2+}$ & 500 \\
$\mathrm{~Pb}^{2+}$ & 500 \\
$\mathrm{Cr}^{3+}$ & 500 \\
$\mathrm{Au}^{3+}$ & 500 \\
\hline
\end{tabular}

${ }^{a}$ Tolerance limit means that the concentration of the coexsitng ions added causes changes in Pd extraction by less than 5\%.

* Unit: $\mu \mathrm{g} \mathrm{mL}^{-1}$ 
as the ratio of the slope of preconcentrated samples to that obtained without preconcentraiton, was 29.

\section{Analytical Application and Method Validation}

In order to examine the accuracy and precision of the proposed method, the extraction procedure was applied to the determination of palladium in the ore standard reference material (GBW07342). The content of palladium in the SRM was $1.67 \pm 0.13 \mu \mathrm{g} \mathrm{g}^{-1}$. Using the method developed in this work, the palladium content found was $1.54 \pm 0.10 \mu \mathrm{g} \mathrm{g}^{-1}(\mathrm{n}=3)$ and the recovery $92.2 \%$. The results showed good agreement with the certified values and the proposed method was confirmed to be feasible for the preconcentration of Pd(II) in samples with complicated matrices.
The developed method was also applied to the palladium determination in fly ash, road dust, and soil samples and satisfactory results were obtained (see Table V). The good recoveries of the standard spiked analysis demonstrate that the method is practical and reliable enough for real sample analysis.

\section{Comparison of the RTIL Extraction with Other Methods}

The determination of palladium by the IL-based micro-extraction method was compared with other reported preconcentration methods for palladium determination and are listed in Table VI. It can be seen that the proposed method has a comparatively low detection limit, a high enrichment factor, and good linear range.

TABLE IV

Analytical Characteristics of the Method $^{\text {a }}$

\begin{tabular}{|c|c|c|}
\hline & Without LLME $^{\mathrm{d}}$ & With LLME ${ }^{\mathrm{d}}$ \\
\hline Concentration range $\left(\mathrm{ng} \mathrm{mL}^{-1}\right)$ & $500-2000$ & $10-500$ \\
\hline Slope & $2 \times 10-5$ & $5 \times 10-4$ \\
\hline Correlation coefficient $\left(\mathrm{R}^{2}\right)$ & 0.9998 & 0.9923 \\
\hline Detecion limit ${ }^{\mathrm{b}}\left(\mathrm{ng} \mathrm{mL} \mathrm{m}^{-1}\right)$ & 64 & 2.2 \\
\hline Relative standard deviation $(\%, n=5)$ & 1.9 & 3.7 \\
\hline Enhancement factor ${ }^{c}$ & - & 29 \\
\hline
\end{tabular}

a Sample volume was $30 \mathrm{~mL}$.

b Determined as $3 \sigma / \mathrm{S}$ ( $\sigma$ and $\mathrm{S}=$ the standard deviation of the blank signal and the slope of the calibration, respectively).

c Calculated as the slope ratio of the calibration obtained with and without preconcentration.

${ }^{\mathrm{d}}$ Liquid-liquid micro-extraction by the present method.

Table V

Analysis of the Real and Spiked Samples by the Present Method (Sample Solution, $\mathbf{n g} \mathbf{m L}^{-1}, \mathbf{n}=3$ )

\begin{tabular}{|c|c|c|c|c|c|}
\hline Sample & Measured $^{\mathrm{a}}$ & Spiked & Found $^{a}$ & $\begin{array}{c}\text { Recovery }^{\mathrm{b}} \\
(\%)\end{array}$ & $\begin{array}{c}\text { Content } \\
\left(\mathrm{ng} \mathrm{g}^{-1}\right)^{\mathrm{c}}\end{array}$ \\
\hline Fly ash & $10.3 \pm 0.7$ & 20.0 & $31.7 \pm 4.9$ & 107 & 516.7 \\
\hline Road dust & $3.7 \pm 0.5$ & 10.0 & $13.7 \pm 0.9$ & 100 & 186.1 \\
\hline Soil & ND & 10.0 & $8.6 \pm 0.6$ & 86 & ND \\
\hline
\end{tabular}

\footnotetext{
a Mean \pm standard deviation.

b $100 \times$ [(found-measured )/spiked].

c Caculated content of Pd in the orginal solid samples.
}

\section{CONCLUSION}

A simple and environmentally friendly method was developed for the preconcentration, separation, and determination of palladium (Pd(II)) in geological and environmental samples. Under optimized experimental conditions, an enhancement factor of 29 was achieved with a $30-\mathrm{mL}$ sample. The limit of

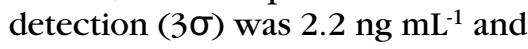
the relative standard deviation (RSD) was 3.7\%.

The novel use of ionic liquid (IL)-based micro-extraction for the preoncentration, separation, and determination of palladium by flame atomic absorption spectrometry (FAAS) is for the first time reported in this study. It can be concluded that IL $\left[\mathrm{C}_{4} \mathrm{MIM}\right]\left[\mathrm{PF}_{6}\right]$ is a good and green extraction solvent for palladium precocentration and separation. Under the optimized experimental conditions, an enhancement factor of 29 was achieved with a 30-mL sample. The limit of detection ( $3 \sigma$ ) was $2.2 \mathrm{ng}$ $\mathrm{mL}^{-1}$, and the relative standard deviation (RSD) was $3.7 \%$ for 7 replicates.

The method was successfully applied to the determination of palladium at low concentrations in digested geological and environmental samples. The performance of the method indicates that the separation and preconcentration procedure is simple, environmentally friendly, rapid, and effective with good accuracy and precision.

\section{ACKNOWLEDGMENT}

This work was kindly co-funded by the Program for New Century Excellent Talents in University (NCET-10-0341), the Fundamental Research Funds for the Central Universities (10ZG01), and the Scientific Research Foundation for the 




TABLE VI

Comparison of the Present Method with Other Preconcentration Methods by FAAS

\begin{tabular}{|c|c|c|c|c|c|c|}
\hline Preconcentration Method & $\begin{array}{l}\text { Detection } \\
\text { Limit } \\
\left(\text { ng mL }{ }^{-1}\right)\end{array}$ & $\begin{array}{l}\text { RSD } \\
(\%)\end{array}$ & $\begin{array}{c}\text { Sample } \\
\text { Volume } \\
\text { (mL) }\end{array}$ & $\begin{array}{c}\text { Calibration } \\
\text { Range } \\
\left(\text { ng mL }^{-1}\right)\end{array}$ & $\begin{array}{c}\text { Enhancement } \\
\text { Factor }\end{array}$ & Ref. \\
\hline Amidinothioureido-silica gel-SPE & 17 & 1.7 & 4.5 & $200-4000$ & - & (31) \\
\hline $\begin{array}{l}\text { Polyamine metalfix-chelamine } \\
\text { resin-SPE }\end{array}$ & 9 & 3.2 & 4.7 & $0.2-2000$ & 20 & (32) \\
\hline $\begin{array}{l}\text { Octadecyl silica membrane disks } \\
\text { modified by thioridazine } \cdot \text { HCl-SPE }\end{array}$ & 12 & 1.2 & 1000 & - & 100 & (33) \\
\hline Activated carbon-SPE & 14 & $<10$ & 200 & - & - & (5) \\
\hline Chloroform-DLLME $^{\mathrm{b}}$ & 90 & 0.7 & 5.0 & $100-2000$ & 45.7 & (34) \\
\hline $\begin{array}{l}\text { Solidified floating organic } \\
\text { drop miroextraction }\end{array}$ & 0.6 & 2 & 15 & $2.0-400$ & 49.9 & (6) \\
\hline$\left[\mathrm{C}_{4} \mathrm{MIM}\right]\left[\mathrm{PF}_{6}\right]-\mathrm{LLME}^{\mathrm{c}}$ & 2.2 & 3.7 & 30 & $10-500$ & 29 & This work \\
\hline
\end{tabular}

${ }^{\mathrm{a}}$ SPE $=$ solid phase extraction; ${ }^{\mathrm{b}}$ DLLME $=$ dispersive liquid-liquid miroextraction; ${ }^{\mathrm{c}}$ LLME $=$ liquid-liquid microextraction.

Returned Overseas Chinese Scholars, State Education Ministry ([2009]1001), P.R. China.

$\overline{\text { Received January 31, } 2011 .}$

\section{REFERENCES}

1. S. Tokalıŏlu, T. Oymak, and S. Kartal, Anal. Chim. Acta 511, 255 (2004).

2. J. Chwastowska, W. Skwara, E. Sterli' nska, and L. Pszonicki, Talanta 64, 224 (2004).

3. K. Boch, M. Schuster, G. Risse, and M. Schwarzer, Anal. Chim. Acta 459, 257 (2002).

4. J. Nakajimaa, M. Ohnoa, K.i Chikamaa, T. Sekia, and K. Oguma, Talanta 79, 1050 (2009).

5. G. Chakrapani, P.L. Mahanta, D.S.R. Murty, and B. Gomathy, Talanta 53, 1139 (2001).

6. M. Mohamadi, A. Mostafavi, Talanta 81, 309 (2010).

7. F. Sánchez Rojas, C. Bosch Ojeda, and J.M. Cano Pavón, Talanta 70, 979 (2006)

8. S. Lin, C. Zheng, and G. Yun, Talanta 42, 921 (1995).

9. X. Jia, T. Wang, and J. Wu, Talanta 54, 741 (2001).
10. G. Philippeit and J. Angerer, J. Chromatogr. B 760, 237 (2001).

11. M. Motelica-Heino, S. Rauch, G.M. Morrison, and O.F.X. Donard, Anal. Chim. Acta 436, 233 (2001).

12. N. Shokoufi, F. Shemirani, and M. Shokoufi, Spectrochim. Acta Part A 74, 761 (2009).

13. D.L. Ma, Y. Wang, K.B. Ma, and J.Y. Wang, Spectr. Spec. Anal. 29, 2833 (2009).

14. M. Muzikar, C. Fontàs, M. Hidalgo, J. Havel, and V. Salvadó, Talanta 70, 1081 (2006).

15. P. Liang, E. Zhao, and F. Li, Talanta 77, 1854 (2009).

16. K. Jankowski, Anal. Chim. Acta 317, 365 (1995).

17. C. Fontàs, V. Salvadó, and M. Hidalgo, Ind. Eng. Chem. Res. 41, 1616 (2002).

18. C.F. Poole and S.K. Poole, J. Chromatogr. A 1217, 2268 (2010).

19. J. Abulhassani, J.L. Manzoori, and M. Amjadi, J. Hazard. Mater. 176, 481 (2010).

20. J.L. Manzoori, M. Amjadi, and J. Abulhassani, Anal. Chim. Acta 644, 48 (2009).

21. J.F. Liu, J.A. Jonsson, and G.B. Jiang, Trends Anal. Chem. 24, 20 (2005).

22. Q.X. Zhou, J.L. Mao, J.P. Xiao, and G.H. Xie, J. Sep. Sci. 33, 1288 (2010).
23. Y. Tao, J.F. Liu, X.L. Hu, H.C. Li, T. Wang, and G.B. Jiang, J. Chromatogr. A 1216, 6259 (2009).

24. J.F. Peng, J.F. Liu, X.L. Hu, and G.B. Jiang, J. Chromatogr. A 1139, 165 (2007).

25. H. Chen, P. Du, J. Chen, S.H. Hu, S.Q. Li, and H.L. Liu, Talanta 81, 176 (2010).

26. S. Dadfarnia, A.M.H. Shabani, M.S. Bidabadi, and A.A. Jafari, J. Hazard. Mater. 173, 534 (2010).

27. E.M. Martinis, P. Berton, R.A. Olsina, J.C. Altamirano, and R.G. Wuilloud, J. Hazard. Mater. 167, 475 (2009).

28. J.D. Li, Y.Q. Cai, Y.L. Shi, S.F. Mou, and G.B. Jiang, Talanta 74, 498 (2008).

29. N. Papaiconomou, J.M. Lee, J. Salminen, M. Stosch, and J.M. Prausnitz, Ind. Eng. Chem. Res. 47, 5080 (2008).

30. M. Vaezzadeh, F. Shemirani, and B. Majidi, Food Chem. Toxicol. 48, 1455 (2010).

31. S. Zhang, Q. Pu, P. Liu, Q. Sun, and Z. Su, Anal. Chim. Acta 452, 223 (2002).

32. M. Iglesias, E. Anticó, and V. Salvadó, Talanta 59, 651 (2003).

33. K. Farhadi and G. Teimouri, Talanta 65, 925 (2005).

34. T.A. Kokya and K. Farhadi, J. Hazard. Mater. 169, 726 (2009). 